\title{
Molecular Characterization of Klebsiella Isolates from Enteral Diets
}

\author{
Pereira $\mathrm{SCL}^{1 *}$ and Vanetti MCD \\ ${ }^{1}$ Universidade Federal de Minas Gerais, Escola de Enfermagem, Departamento de Nutrição, Belo Horizonte-MG, Brazil
}

${ }^{2}$ Universidade Federal de Viçosa, Departamento de Microbiologia, Viçosa-MG, Brazil

\begin{abstract}
To evaluate the genotyping of Klebsiella isolates from enteral diets in public hospitals, as high-resolution support within epidemiological surveillance for controlling nosocomial infections. Methods: Klebsiella isolates were obtained from enteral diets at two public hospitals in the state of Minas Gerais, Brazil. These isolates were identified and serotyped. Total DNA of Klebsiella was extracted and subjected to three genotyping methods, to evaluate polymorphism between the strains and genetic diversity. Results: Twenty-one isolates of Klebsiella were obtained from the hospital enteral formulae; fifteen were identified as $K$. pneumoniae and six as $K$. oxytoca. The results from random amplified polymorphic DNA (RAPD) and 16S-23S rDNA analysis revealed high polymorphism among the $K$. pneumoniae isolates and a low level of polymorphism among the $K$. oxytoca isolates. The 1420 base pairs of DNA fragments generated through amplification of the 16S rDNA region and digestion with eight restriction endonucleases resulted in identical restriction fragment length polymorphism (RFLP) patterns for all isolates. Conclusion: Our data demonstrate that RAPD and 16S-23S rDNA analyses provide more reliable estimates of the genetic diversity among Klebsiella isolates than does amplification of the 16S rDNA gene. Therefore, we recommend that RAPD typing should be the preliminary method for fast and inexpensive investigation and that 16S-23S rDNA typing should be a confirmatory method if needed.
\end{abstract}

\section{Keywords: Enteral diets; Klebsiella; Genotyping}

\section{Introduction}

Klebsiella is a paradigm for opportunistic pathogens among Gramnegative bacilli and is associated with nosocomial infections. Resistance of the species K. pneumoniae to most antibiotics is on the rise [1]. In a review on surveillance surveys, the majority of episodes of nosocomial $K$. pneumoniae bacteremia were caused by extended-spectrum $\beta$-lactamase (ESBL)-producing strains [2]. Higher frequencies have been reported in some areas, such as Brazil, where up to $50 \%$ of the isolates in bloodstream infections were ESBL-producing strains of $K$. pneumonia [3]. Moreover, Klebsiella spp. is one of the most frequent contaminating bacteria found in enteral diets, i.e., the feeding method used for patients under intensive care [4,5]. Little attention has been paid to the role of Klebsiella and other intestinal foodborne pathogens in nosocomial infections, although bacteria that colonize the intestinal tract are the main cause of infections in hospitalized patients [6].

Klebsiella has recently been correlated with chronic intestinal diseases. The results of studies and reviews support the idea that $K$. pneumoniae is the most likely triggering factor involved in the initiation and development of ankylosing spondylitis and Crohn's disease [7]. Members of the family Enterobacteriaceae, particularly the species Klebsiella oxytoca, have been found to be more abundant in patients with active celiac disease than in controls [8].

In a noteworthy recent study, rapid and widespread dissemination of an epidemic clone of $K$. pneumoniae was found to cause a large nosocomial outbreak through the food chain. To our knowledge, this was the first report to provide insight on how transmission of multiresistant. Klebsiella can occur through food, as the vehicle in the hospital setting [9]. Thus, identification of the source of infection in hospital environments is a strategy for reducing the infection rate. Epidemiological studies on Klebsiella based on genotype characterization provide a suitable and accurate approach for identification purposes, thereby allowing discrimination below the strain level $[1,10,11]$. Compared with phenotyping, genotyping has become widely used for bacterial strain typing because of its higher resolution. Among different genotyping methods, the time and costeffectiveness of DNA banding pattern-based typing methods have made these methods matters of interest [10]. In this light and given that few studies have been conducted on the molecular epidemiology of Klebsiella spp. isolates from foods destined for critical patients, the present work aimed to screen for the presence and determine the strain types of Klebsiella sp. present as contaminants in enteral diets served to patients admitted to two hospital units located in the State of Minas Gerais, Brazil.

\section{Methods}

Isolation, identification and serotyping of Klebsiella from enteral diets

Modular industrialized (milk-based and food supplement) enteral diets (30 samples) as used in two public hospitals in the State of Minas Gerais (Brazil) were analyzed, and Klebsiella sp. isolates were obtained from six (20\%) of them. We emphasize that the samples were collected before administration to the patients. Typical Klebsiella colonies were isolated from these samples on MacConkey-inositol-carbenicillin selective medium [12]. Three to five typical colonies of each sample were placed on tryptic soy agar (TSA) (Oxoid, Basingtoke, Hampshire, England), and maintained on semisolid brain heart-infusion (BHI) (Oxoid), at $4^{\circ} \mathrm{C}$. The isolates were identified by the API 20E System (API, Bio Meriex, L'Etole, France) and confirmed by the Crystal System

*Corresonding author: Pereira SCL, Universidade Federal de Minas Gerais Escola de Enfermagem, Departamento de Nutrição, Belo Horizonte-MG, Brazil, Tel: 553134098028; E-mail: simoneclpereira@gmail.com

Received October 19, 2015; Accepted November 09, 2015; Published November 12, 2015

Citation: Pereira SCL, Vanetti MCD (2015) Molecular Characterization of Klebsiella Isolates from Enteral Diets. J Food Process Technol 6: 528 doi:10.4172/21577110.1000528

Copyright: @ 2015 Pereira SCL, et al. This is an open-access article distributed under the terms of the Creative Commons Attribution License, which permits unrestricted use, distribution, and reproduction in any medium, provided the original author and source are credited. 
(BBL-Becton \& Dickinson, Bedford, MA, USA), at the Enterobacteria Laboratory of the Bacteriology Department, Oswaldo Cruz Foundation, Brazil. Serological tests were performed with antigens K1 to K6.

\section{RAPD analysis}

Total DNA of Klebsiella was extracted as described by Martins et al. Amplification reactions were carried [13]. The $25 \mu \mathrm{l}$ reaction mixture consisted of $10 \mathrm{mM}$ Tris- $\mathrm{HCl}, \mathrm{pH} 8.0,50 \mathrm{mM} \mathrm{KCl}, 2.0 \mathrm{mM} \mathrm{MgCl}_{2}$, $0.1 \mathrm{mM}$ dNTP, $0.4 \mu \mathrm{M}$ RAPD primer, 1.0 U Taq DNA polymerase (Promega), and $25 \mathrm{ng}$ total DNA. The primers OPD03, OPD07, OPD08, OPD12, OPD18, OPD20, OPF10, and OPF13 were purchased from Operon Technologies (Inc., Alameda, CA, EUA). A thermal cycling was performed in a PTC 100 machine (MJ Research Inc., Waterton, MA, EUA) programmed for an initial denaturation step at $94{ }^{\circ} \mathrm{C}$ for 5 min, followed by 30 cycles of $1 \mathrm{~min}$ at $94{ }^{\circ} \mathrm{C}, 1 \mathrm{~min}$ at $40{ }^{\circ} \mathrm{C}$, and $1.30 \mathrm{~min}$ at $72{ }^{\circ} \mathrm{C}$. A final extension at $72{ }^{\circ} \mathrm{C}$ for $7 \mathrm{~min}$ was performed. Amplification products were analyzed by electrophoresis on a $1.5 \%$ agarose gels in order to facilitate the electrophoresis analysis. The gels were photographed under UV light using an Eagle-Eye II video system (Stratagene, La Jolla, CA, USA).

\section{rDNA analysis}

Total DNA from each Klebsiella isolate was amplified using 16S rDNA primers (5' GCCTAACACATGCAAGTCGA and 3' AAAGTGGTAAGCGCCCTCCC) and the 16S-23S rDNA intergenic transcribed spacer (ITS) region (5' GGTGAAGTCGTAACAAG and 5' TGCCAAGGCATCCACC). DNA templates $(20 \mathrm{ng})$ were amplified in a $25 \mu \mathrm{l}$ reaction volume containing $1 \mathrm{U}$ Taq polymerase (Promega), 0.5 $\mu \mathrm{M}$ of each primer, $0.2 \mathrm{mM}$ of each of the four dNTPs (Promega), $1 \mathrm{X}$ PCR buffer (10 mM Tris- $\mathrm{HCl}, \mathrm{pH}$ 8.0, $50 \mathrm{mM} \mathrm{KCl}, 2.0 \mathrm{mM} \mathrm{MgCl}$ ). PCR amplification was performed with a PTC 100 thermal cycle. After an initial denaturation step of $5 \mathrm{~min}$ at $94^{\circ} \mathrm{C}$, a total of 40 cycles of amplification was performed using the following thermal profile: $1 \mathrm{~min}$ at $94^{\circ} \mathrm{C}$ (denaturation), $1 \mathrm{~min}$ at $56^{\circ} \mathrm{C}$ (annealing) and $1 \mathrm{~min}$ at $72^{\circ} \mathrm{C}$ (elongation) followed by a $7 \mathrm{~min}$ extension step at $72^{\circ} \mathrm{C}$. Controls were included in each set of amplifications, namely, a reaction mixture with distilled water instead of template DNA. To assess PCR reproducibility, two independent PCR amplifications were performed for each strain included in this study. $16 \mathrm{~S}$ rDNA-amplified products were electrophoresed on a $1.5 \%$ agarose gel or ethanol precipitated for the restriction analysis with BglI, HhaI, HindIII, HinfI, KpnI, and XhoI. Restriction fragments were visualized following gel electrophoresis on $2 \%$ agarose gel. PCR products for the ITS region Amplification products were analyzed by electrophoresis on a $1.5 \%$ agarose gels in order to facilitate the electrophoresis analysis. The gels were photographed under UV light using an Eagle-Eye II video system (Stratagene, La Jolla, CA, USA).

\section{Analysis of molecular data}

Banding patterns from RAPD and ITS analysis were scored as 1 (presence) or 0 (absence) and used for determination of the genetic diversity among Klebsiella isolates. The presence of the same size bands in genotypes indicates similarity, while the presence in one genotype and absence in the others indicates dissimilarity. Negative controls, amplifications reactions without DNA, were used in all primer amplifications. In addition, some RAPD reactions were also repeated. The data were analyzed by the statistical software GENES [14]. The genetic diversity values $\left(\mathrm{GD}_{i j}\right)$ were calculated using the Jaccard's coefficient [15].
Cluster analysis was carried out using the Unweighted Pair Group Method Using Arithmetic Averages (UPGMA) provided by Statistic version 4.2, and by multidimensional scaling biplot [16]. The Tocher optimization method was also used to aid in the characterization of the groups as described by Cruz and Carneiro [15]. Hierarchical grouping methodologies and Tocher' optimization were used to cluster the less genetically divergent isolates [15].

\section{Results}

Twenty-one isolates derived from enteral diets were identified as Klebsiella, six was K. oxytoca and eleven was K. pneumoniae (Table 1). Among the K. pneumoniae, five isolates belonged to the serological group K5 and one to group K4. Analysis of the genetic diversity of $K$. pneumoniae isolates by RAPD showed a remarkable polymorphism as 31 polymorphic DNA fragments were detected against only two monomorphic (data note shown). Strains from the serogroup K5 (numbers 8, 11, 15, 17 and 21) (Table 1) revealed different band profiles, whereas no difference could be seen between the isolates 7 and 8 that belong to different serotypes. The UPGMA analysis resulted in three K. pneumoniae groups with genetic diversity up to $73.9 \%$. The isolates originated from the hospital unit A formed two groups and all isolates from the hospital unit B were grouped together (Figure 1a).

RAPD markers revealed a low level of polymorphism among $K$. oxytoca isolates and sixteen monomorphic and nine polymorphic bands were detected on the agarose gel (data note shown). These isolates were originated from the same hospital unit, but they were separated into three genetically related groups with genetic distances varying between 2.4 and $20 \%$ (Figure $1 \mathrm{~b}$ ). The amplification of the $16 \mathrm{~S}-23 \mathrm{~S} \mathrm{rDNA}$ intergenic spacer region of $K$. pneumoniae and $K$. oxytoca generated monomorphic and polymorphic DNA fragments, respectively. The banding profile clearly differentiated each species. Three monomorphic and five polymorphic bands were visualized for K. pneumoniae isolates (Figure 2). The UPGMA analysis resulted in two clusters: the first cluster (Group I) was formed by isolates obtained from enteral diets derived from hospital B and the second cluster (Group II) was formed

\begin{tabular}{|c|c|c|c|c|c|c|}
\hline No. & Sample & Isolates & Enteral diet & Species & Sorogroup & Hospital \\
\hline 1 & 1 & $\mathrm{P} 1$ & $\mathrm{NI}^{\mathrm{a}}$ & K. oxytoca & $-{ }^{-}$ & $\mathrm{A}$ \\
\hline 2 & 1 & $\mathrm{P} 2$ & $\mathrm{NI}$ & K. oxytoca & - & $\mathrm{A}$ \\
\hline 3 & 1 & $\mathrm{P} 3$ & $\mathrm{NI}$ & K. oxytoca & - & $\mathrm{A}$ \\
\hline 4 & 1 & $\mathrm{P} 4$ & $\mathrm{NI}$ & K. oxytoca & - & $\mathrm{A}$ \\
\hline 5 & 1 & $\mathrm{P} 5$ & $\mathrm{NI}$ & K. oxytoca & - & $\mathrm{A}$ \\
\hline 6 & 3 & $\mathrm{P} 6$ & $\mathrm{NI}$ & K. pneumoniae & $\mathrm{nd}$ & $\mathrm{A}$ \\
\hline 7 & 3 & $\mathrm{P} 7$ & $\mathrm{NI}$ & K. pneumoniae & $\mathrm{nd}$ & $\mathrm{A}$ \\
\hline 8 & 3 & $\mathrm{P} 8$ & $\mathrm{NI}$ & K. pneumoniae & $\mathrm{K} 5$ & $\mathrm{~A}$ \\
\hline 9 & 3 & $\mathrm{P} 9$ & $\mathrm{NI}$ & K. oxytoca & - & $\mathrm{A}$ \\
\hline 10 & 4 & $\mathrm{P} 11$ & $\mathrm{NI}$ & K. pneumoniae & $\mathrm{nd}$ & $\mathrm{A}$ \\
\hline 11 & 4 & $\mathrm{P} 13$ & $\mathrm{NI}$ & K. pneumoniae & $\mathrm{K} 5$ & $\mathrm{~A}$ \\
\hline 12 & 4 & $\mathrm{P} 14$ & $\mathrm{NI}$ & K. pneumoniae & $\mathrm{nd}$ & $\mathrm{A}$ \\
\hline 13 & 4 & $\mathrm{P} 15$ & $\mathrm{NI}$ & K. pneumoniae & $\mathrm{nd}$ & $\mathrm{A}$ \\
\hline 14 & 4 & $\mathrm{P} 17$ & $\mathrm{NI}$ & K. pneumoniae & $\mathrm{nd}$ & $\mathrm{A}$ \\
\hline 15 & 5 & $\mathrm{U} 1$ & $\mathrm{NIM}$ & K. pneumoniae & $\mathrm{K} 5$ & $\mathrm{~B}$ \\
\hline 16 & 5 & $\mathrm{U} 2$ & $\mathrm{NIM}$ & K. pneumoniae & $\mathrm{nd}$ & $\mathrm{B}$ \\
\hline 17 & 5 & $\mathrm{U} 3$ & $\mathrm{NIM}$ & K. pneumoniae & $\mathrm{K} 5$ & $\mathrm{~B}$ \\
\hline 18 & 5 & $\mathrm{U} 4$ & $\mathrm{NIM}$ & K. pneumoniae & $\mathrm{nd}$ & $\mathrm{B}$ \\
\hline 19 & 6 & $\mathrm{U} 5$ & $\mathrm{NIM}$ & K. pneumoniae & $\mathrm{K} 4$ & $\mathrm{~B}$ \\
\hline 20 & 6 & $\mathrm{U} 7$ & $\mathrm{NIM}$ & K. pneumoniae & $\mathrm{nd}$ & $\mathrm{B}$ \\
\hline 21 & 6 & $\mathrm{U} 8$ & $\mathrm{NIM}$ & K. pneumoniae & $\mathrm{K} 5$ & $\mathrm{~B}$ \\
\hline
\end{tabular}

Table 1: Identification, serotyping and characteristics of Klebsiella spp isolated from enteric diets. 
Citation: Pereira SCL, Vanetti MCD (2015) Molecular Characterization of Klebsiella Isolates from Enteral Diets. J Food Process Technol 6: 528. doi:10.4172/2157-7110.1000528

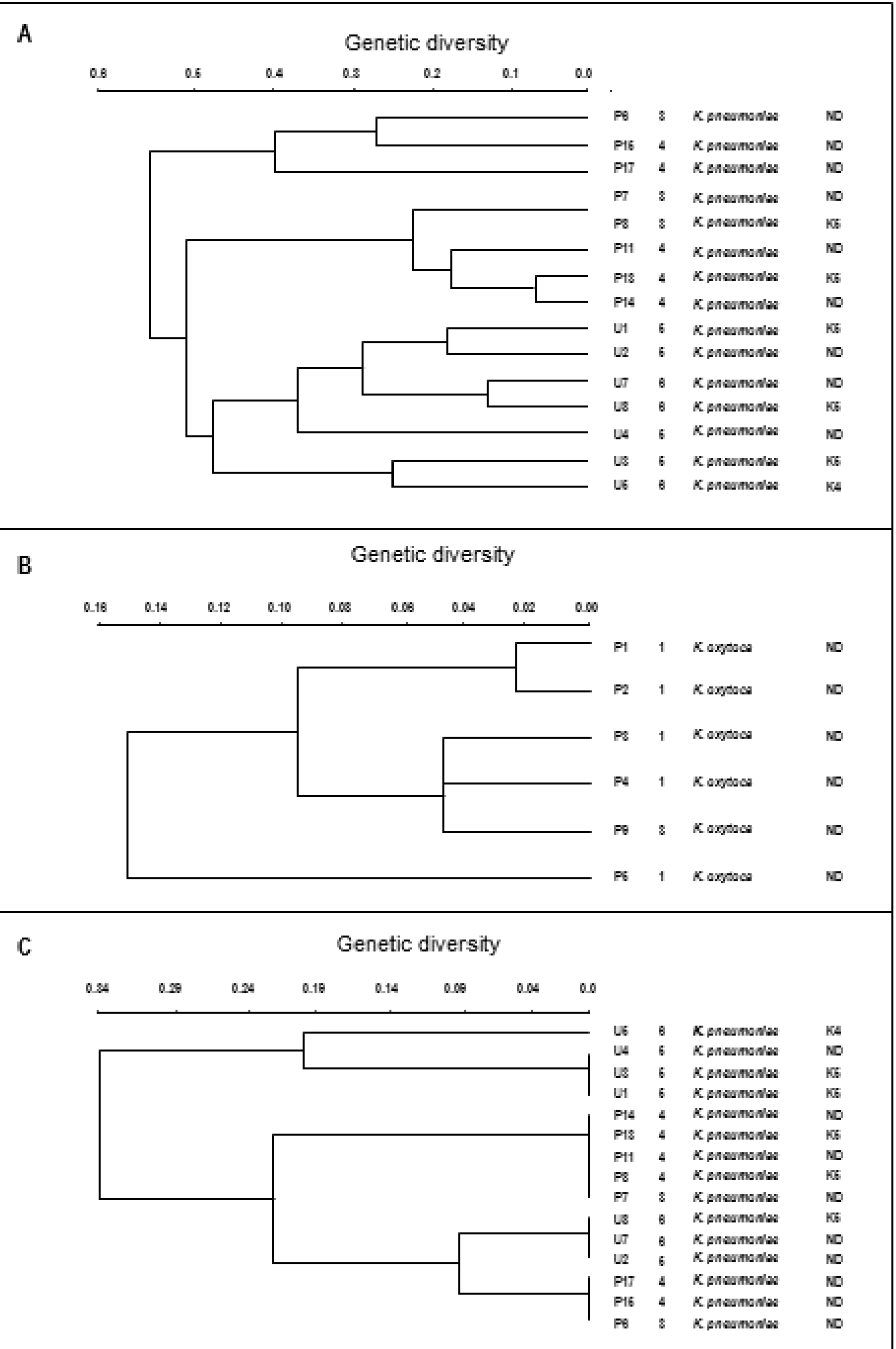

Figure 1: Dendrograms geraded by genotype grouping of isolates $K$. pneumoniae (A and C) and $K$. oxytoca (B) from enteral diets based in genetic similarity coefficient determined by amplied DNA for RAPD patterns with eight primer: OPD03, OPD07, OPD08, OPD12, OPD20, OPF10 e OPF13 (A and B) and based in genetic similarity coefficient determined by amplied DNA for 16S-23S rDNA spacer region patterns (C). The identification of $K$. pneumoniae corresponds to isolated, sample, species, and serogroup. The identificationof $K$. oxytoca corresponds to isolate, sample, and specie nd $=$ not determinate. 
(A)

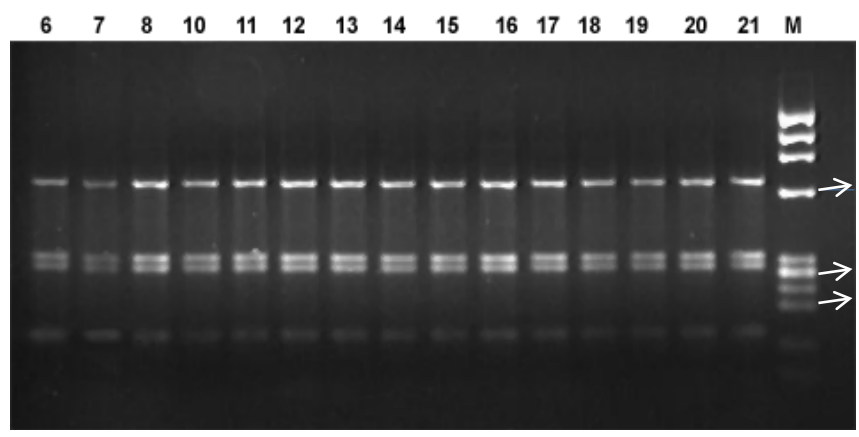

(B)

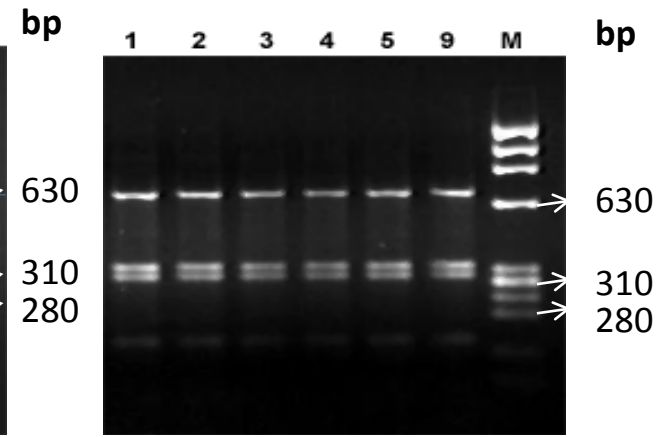

Figure 2: Agarose gel electrophoresis of amplied rDNA spacer region 16-23S of Klebsiella spp isolates. A- Lanes 6 to 21 correspond to isolate of K. pneumoniae B from enteral diets listed in Table 1. Lane M: Molecular size marker ( $\varphi \times 174$ phagos DNA, HaellI digested).

by isolates coming from both hospitals (Figure 1c). The highest genetic diversity obtained between isolates from different hospital units and isolates from hospital B was $45 \%$. Total similarity was only detected among isolates originated from the same hospital.

The Pearson's correlation coefficient of data generated by RAPD and ITS analysis of $K$. pneumoniae isolates was $0.34 \quad(\mathrm{p}<0.01)$. Amplification of K. pneumoniae and K. oxytoca total DNA with $16 \mathrm{~S}$ rDNA gene primers produced a fragment of approximately $1420 \mathrm{bp}$. Size polymorphism was not detected among Klebsiella isolates (Figure 3). No restriction polymorphism was found among the isolates. The $1420 \mathrm{bp}$ fragment was checked for the presence of restriction sites with the enzymes HinfI, BglI, EcoRI, and HhaI. The absence of internal sites for EcoRV, HindIII, KpnI, and XhoI was also assessed by the visualization of a single $1420 \mathrm{bp}$ DNA fragment.

\section{Discussion}

The presence of Klebsiella in enteral diets needs to be considered as a possible source of contamination of hospitalized patients. This arises because enteral diets are especially prescribed for patients concentrated in intensive care units who are highly susceptible to nosocomial infections. These are patients who are subjects to the intrinsic risks of nosocomial infections relating to complex underlying diseases, nutritional vulnerability, extreme ages (premature babies and elderly people) and the effects of immunosuppressant and/or immunodepressive drugs and broad-spectrum antimicrobial agents. Furthermore, these patients are subject to extrinsic risks such as having a prolonged stay in the hospital environment, being subjected to a routine of invasive procedures and lacking guaranteed quality in all hospital services, given the complex nature of the organization.

Nosocomial infections are a worldwide problem because of their impact in clinical, ethical and financial terms [17]. Control programs for these infections have been developed and implemented, but the rates of such infections have not become significantly reduced, especially because of the challenge of occurrences of outbreaks that are difficult to control because of the appearance of multiresistant hospital bacteria. For many of these microbial strains, the therapeutic options are very limited and have a high cost [17-19]. In Brazil, the problem of nosocomial infections is increasing all the time. Even with the country's current legislation, nosocomial infection rates are high (15.5\%). Moreover, the fact that public healthcare institutions present the highest prevalence of nosocomial infections in the country $(18.4 \%)$ can be considered to be an aggravating factor $[19,20]$.

The enteral diets analyzed were more frequently contaminated with $K$. pneumoniae, but also showed contamination with $K$. oxytoca. These species are involved in nosocomial and community infections [21,22]. Six out of the fifteen $K$. pneumoniae isolates belonged to serological groups $\mathrm{K} 1$ and $\mathrm{K} 2$, which are frequently regarded as endemic in hospital environments and associated with nosocomial infections [2].

With regard to the presence of these bacteria in the hospital dietary sector, another study conducted by the authors of the present study (data not yet published) indicated that $K$. pneumoniae was the bacterium most frequently found in all the samples analyzed (35.4\% of the total), from food handlers, utensils and food processing surfaces. Recently, Ekrami et al. found a situation similar to that of the present study in seven hospital food services, with contamination caused by $S$. aureus and K. pneumonia [23]. There was significant presence of these microorganisms on food handlers' hands $(79.5 \%)$, processing surfaces (71.4\%), clothing (61.1\%) and equipment (57.8\%). Furthermore, this study found that Gram-negative bacteria were present on $50 \%$ of the hands that manipulated foods [24].

Corroborating these findings, the study by Calbo et al described the epidemiology of and control measures taken in relation to a foodborne nosocomial outbreak of $K$. pneumoniae in an acute care hospital [9]. This report described rapid and widespread dissemination of an epidemic clone of K. pneumoniae, which caused a large nosocomial outbreak through the food chain. To our knowledge, this was the first report to provide insight on how transmission of $K$. pneumoniae can occur through food as the vehicle in the hospital setting. The outbreak was stopped only after control measures were applied in the kitchen. The absence of new cases during the 14-month follow-up period suggests that these measures were effective [9]. In the present study, Klebsiella was isolated from enteral diets and subjected to molecular characterization as a first step towards discriminating between strains for further evaluation of their possible association with clinical isolates of this bacterium in outbreaks of nosocomial infections. These data are relevant for epidemiological surveillance because they enable identification and early intervention, thereby reducing the risk of nosocomial infections that involve the nutrition service, especially with regard to diets destined for critical patients [19]. RAPD detected genetic variation within $K$. pneumoniae isolated from enteral diets. 
(A)

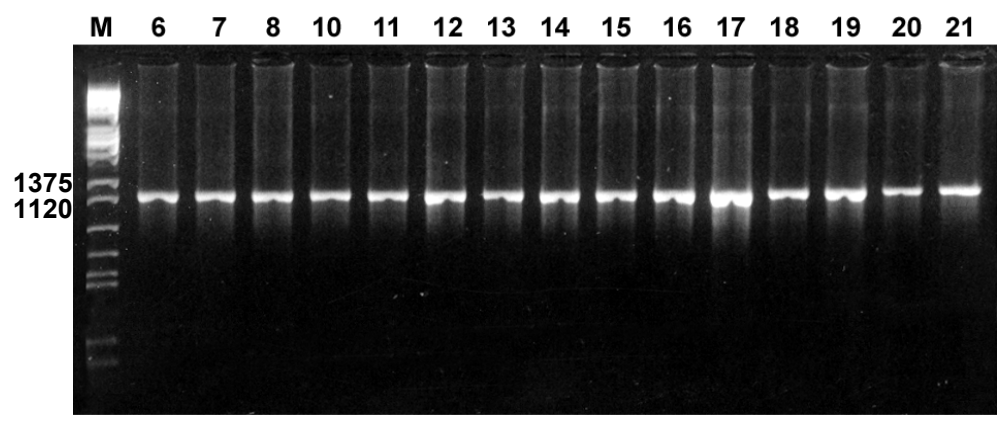

(B)

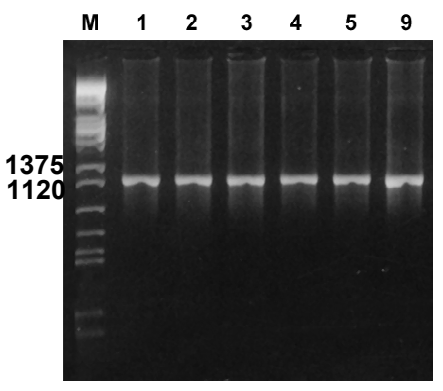

Figure 3: Agarose gel electrophoresis of amplied rDNA region 16S of $K$. pneumoniae (A) and K. oxytoca (B). Lanes 1 to 21 correspond to isolate listed in Table 1. Lane M: Molecular size marker ( $\lambda$ phagos DNA, HindIII-BanHI-EcoRI digested).

Similar results were found for the clinical isolates. The ability of RAPD analysis to discriminate between strains was confirmed by our results. The amplified DNA fragments were not specific for any given serological group. In a recent study, the discriminatory power of the pulsed-field gel electrophoresis (PFGE) and random amplified polymorphic DNA (RAPD) methods for subtyping 54 clinical isolates of Klebsiella pneumoniae were compared. All the isolates were typable by means of RAPD, while $3.6 \%$ of them were not typable by means of PFGE. ${ }^{24}$ PFGE is considered to be the gold standard for typing $K$. pneumonia. The repeatability of the two typing methods was $100 \%$, with satisfactory reproducibility (95\%). It was concluded that an optimized RAPD protocol is technically less demanding and time consuming, which makes it a reliable typing method that is competitive with PFGE $[10,25]$.

Differences between K. pneumoniae isolates originating from the same sample or from the same place were demonstrated by the genetic distance obtained. The genetic distance was $73.9 \%$ in strains isolated from samples of enteral diets collected in hospital unit A (numbers 11 and 14). However, strain number 6 , from hospital A, was $94 \%$ similar to strain number 19, derived from hospital B. These differences can be explained in terms of concomitant amplification of plasmid DNA [24]. This variation may also be due to loss of these plasmids caused by the stress conditions faced by K. pneumoniae strains [11]. Another possible explanation for the genetic diversity seen in this work may be the different sources of contamination in the hospital food service. High incidence of $K$. pneumoniae was found on equipment, tools, food handlers' hands and work surfaces in the nutritional and dietary sectors of the hospitals [23]. Klebsiella isolates were also shown to present amplification of the 16S-23S rDNA intergenic transcribed spacer region. Our data also demonstrated that RAPD and ITS analyses were more reliable for estimating genetic diversity between Klebsiella isolates than amplification of the 16S rDNA gene. However, the 16S region did not differentiate between the strains of Klebsiella in the present study. On the other hand, the importance of using this betterconserved region for the purposes of identifying the bacterial genus was highlighted. Evaluation of the $16 \mathrm{~S}$ rDNA region would thus be applicable as a second stage as a confirmatory test for the presence of Klebsiella. In this regard, a recent study using this region for molecular identification found that a gene originating from $V$. cholera that was a novel variant of the cholera toxin gene $(\operatorname{ct} x A B)$ was present in other enterobacteria, including Klebsiella [11].

\section{Final Remarks}

Our results showed that ITS and optimized RAPD are equally valuable for typing Klebsiella isolates from enteral diets. Since RAPD is less technically demanding and time consuming, we recommend that RAPD typing should be the preliminary method for fast and inexpensive investigation and that ITS typing should be a confirmatory method if needed. Compared with phenotyping, the higher resolution of genotyping can contribute towards the basis for other studies on the distribution of nosocomial infections and their determinants that would be aimed towards preventive actions.

In this regard, the present study brings together knowledge on nosocomial infections and emphasizes the importance of measures relating to outcomes associated with the nutrition sector, with the aim of strengthening the interfaces between infection control and preventive actions and between such control and quality promotion within care services overall. It also endorses the need to direct healthcare funding policies towards adopting risk control and prevention measures in strategic sectors of the healthcare services. There is a need to reflect on all the possible strategies that might contribute towards changing the current panorama within which nosocomial infections are presented, with investment in research and updating. It should be emphasized that nosocomial infection control is grounded in results and that, from this, support within the organization can be obtained, given that its consequences for the quality of care are sufficient to justify maintaining such controls. Genotyping data support epidemiological surveillance, which thus constitutes an important instrument for planning, organizing and putting into operation healthcare services, as well as for providing standards for technical activities. This information adds knowledge on nosocomial infections and aids in detecting or preventing changes to the conditioning factors of such infections, so that timely and well-grounded recommendations can be made for appropriate and efficient measures that lead to prevention and control of these infections. It should be emphasized that dissemination of data analyses such as in the present study and other recent studies should be done routinely among all the healthcare and administrative professionals of hospital institutions. Many professionals will, through becoming aware of the results relating to their own specific services, start to rethink their practices and become more involved in prevention and control practices, with surveillance in its true sense. Thus, the information disseminated may have a significant impact on nosocomial infection rates. 
Citation: Pereira SCL, Vanetti MCD (2015) Molecular Characterization of Klebsiella Isolates from Enteral Diets. J Food Process Technol 6: 528. doi:10.4172/2157-7110.1000528

Page 6 of 6

\section{References}

1. Lin YT, Wang FD, Chan YJ, Fu YC, Lin CPF, et al. (2014) Clinical and microbiological characteristics of tigecycline non-susceptible Klebsiella pneumoniae bacteremia in Taiwan. BMC Infect.

2. Viale P, Giannella M, Lewis R, Trecarichi EM, Petrosillo N, et al. (2013) Predictors of mortality in multidrug-resistant Klebsiella pneumoniae bloodstream infections. Expert Review of Anti-infective Therapy 11: 1053-1063.

3. Marra AR, Wey SB, Castelo A, Gales AC, Cal RG, et al. (2006) Nosocomial bloodstream infections caused by Klebsiella pneumoniae: Impact of extendedspectrum beta-lactamase (ESBL) production on clinical outcome in a hospital with high ESBL prevalence. BMC Infect Dis.

4. Arias ML, Monge R, Chávez C (2003) Microbiological contamination of enteral feeding solutions used in Costa Rican hospitals. Arch Latinoam Nutr 53: 277-281.

5. Hurrell E, Kucerova E, Loughlin M, Caubilla-Barron J, Hilton A, et al. (2009) Neonatal enteral feeding tubes as loci for colonisation by members of the Enterobacteriaceae. BMC Infect Dis 9: 146-174.

6. Westerbeek EAM, Berg AVD, Lafeber HN, Fetter WPF, Elburg RMV, et al. (2011) The effect of enteral supplementation of a prebiotic mixture of non-human milk galacto-, fructo- and acidic oligosaccharides on intestinal permeability in preterm infants. British Journal of Nutrition 105: 268-274.

7. Rashid T, Wilson C, Ebringer A (2013) The Link between Ankylosing Spondylitis, Crohn's Disease, Klebsiella, and Starch Consumption. Clinical and Developmental Immunology.

8. Sánchez E, Donat E, Ribes-Koninckx C, Fernández-M urga ML, Sanz Y (2013) Duodenal-Mucosal Bacteria Associated with Celiac Disease in Children. Applied and Environmental Microbiology 79: 5472-5479.

9. Calbo E, Freixas N, Xercavins M, Riera M, Nicola's C, et al. (2011) Foodborne nosocomial outbreak of SHV1 and CTX-M-15-producing Klebsiella pneumoniae: Epidemiology and control. Clin Infect Dis 52: 743-749.

10. Li W, Raoult D, Fournier PE (2009) Bacterial strain typing in the genomic era. FEMS Microbiol Rev 33: 892-916.

11. Shibata Y, Nomoto R, Vries GC, Osawa R (2013) Serendipitous Isolation of NonVibrio Bacterial Strains Carrying the Cholera Toxin Gene from Environmenta Waters in Indonesia. Hindawi Publishing Corporation International Journal of Microbiology.

12. Bagley ST, Seidler RJ (1978) Primary Klebsiella identification with MacConkeyinositol-carbenicilin agar. App Environ Microbiol 36: 536-538.
13. Martins ML, Araújo EF, Mantovani HC, Moraes CA, Vanetti MCD, et al. (2005) Detection of the apr gene in proteolytic psychrotrophic bacteria isolated from refrigerated raw milk. International Journal of Food Microbiology 102: 203-211.

14. Cruz CD (2001) Programa Genes-versão Windows. Editora UFV, Viçosa.

15. Cruz CD, Carneiro PCS (2003) Modelos Biométricos Aplicados ao Melhoramento Genético, Viçosa.

16. Dias LAS (1998) Análises multidimensionais. Eletroforese de Isoenzimas e Proteínas Afins: Fundamentos e Aplicações em Plantas e Microrganismos. Viçosa.

17. World Health Organization (2011) Core components for infection prevention and control programs. Assessment tools for IPC programmes, Geneve.

18. Ministério da Saúde (BR) (1998) Expede na forma de anexos diretriz e normas para a prevenção e controle das infecções hospitalares: Portaria $N^{\circ} 2.616$ de 12 de maio de. Diário Oficial da União, República Federativa do Brasil, Brasília (DF).

19. Maruyama SAT (2008) Controle de infecção hospitalar: Histórico e papel do estado. Rev Eletr Enf 10: 775-83

20. Prade SS (1995) Estudo Brasileiro da Magnitude das Infecões Hospitalares em Hospitais Terciários. Rev Cont Infec Hosp 2.

21. Keynan Y, Rubinstein E (2007) The changing face of Klebsiella pneumoniae infections in the community. International Journal of Antimicrobia Agents 30: 385-389.

22. Ifeadike CO, Ironkwe OC, Adogu POU, Nnebue CC, Emelumadu OF, et al. (2012) Prevalence and pattern of bacteria and intestinal parasites among food handlers in the Federal Capital Territory of Nigeria. Niger Med J 53: 166-171.

23. Ekrami AR, Kayedani A, Jahangir M, Kalantar E, Jalali M, et al. (2011) Isolation of common aerobic bacterial pathogens from the environment of seven hospitals, Ahvaz, Iran. Jundishapur J Microbiol 4: 75-82.

24. Mitra AP, Fereshteh E, Mobarak GM, Mahmood P, Mehdi FM, et al. (2013) Genetic profiling of Klebsiella pneumoniae: Comparison of pulsed field ge electrophoresis and random amplified polymorphic DNA. Braz J Microbiol 44 823-828.

25. Arlet G, Rouveau M, Casin I, Bouvet PJ, Lagrange PH, et al. (1994) Molecular epidemiology of Klebsiella pneumoniae strains that produce SHV-4 betalactamase and which were isolated in 14 French hospitals. J Clin Microbiol 32 2553-2558. 